\title{
Variables Sociodemográficas y Académicas Explicativas de la Deserción de Estudiantes en la Facultad de Ciencias Naturales de la Universidad de Playa Ancha (Chile)
}

\author{
Cristian M. Carvajal(1), José A. González ${ }^{(1)}$ y Silvia J. Sarzoza(2) \\ (1) Universidad de Playa Ancha, Fac. de Ciencias, Laboratorio Experimental de Saberes Matemáticos \\ (LABESAM). Avda. Leopoldo Carvallo 270, Playa Ancha, Valparaíso-Chile. \\ (e-mail: cristian.carvajal@upla.cl). \\ (2) Universidad de Playa Ancha, Dirección de Escuela de Postgrado. Playa Ancha 850, Valparaíso-Chile.
}

Recibido Jul. 10, 2017; Aceptado Sep. 25, 2017; Versión final Nov. 21, 2017, Publicado Abr. 2018

\begin{abstract}
Resumen
Este artículo presenta un análisis explicativo, tomando como efecto la deserción universitaria y como causas un conjunto de variables predictoras. El estudio se focalizó en los estudiantes de la Universidad de Playa Ancha, en Chile. El estudio propone como objetivo la identificación de los factores que influyen de manera significativa en el proceso de deserción de los estudiantes de la Universidad de Playa Ancha y, cuantificar el efecto individual de cada predictor en la respuesta de un modelo estadístico. Basado en la dicotomía de la variable dependiente, se utilizó un modelo logístico con función de enlace binomial. El proceso de ajuste del modelo se desarrolló en dos etapas. Primero se estimaron los efectos individuales de cada variable predictora, seleccionando de entre ellas las significativas. En segundo lugar, se descartaron aquellas con efectos no significativos propendiendo un modelo parsimonioso. SE concluye que las variables que afectan directamente a la deserción son los predictores de primer orden, Ramos Aprobados (RA), Orden de Lista (OL), Estado Civil (EC) y Educación del Padre (EP).
\end{abstract}

Palabras clave: deserción; modelo logístico; educación superior; desigualdad educativa; análisis estadístico

\section{Sociodemographic and Academic Variables Explaining Student's Dropout in the Faculty of Natural Sciences of the University of Playa Ancha (Chile)}

\begin{abstract}
This article presents an explanatory analysis, taking as an effect the university dropout and as causes a set of predictor variables. The study focused on students of the University of Playa Ancha in Chile. The objective of the study was the identification of the factors that significantly influence the desertion process of the students of the Playa Ancha University and quantify the individual effect of each predictor. Based on the dichotomy of the dependent variable, a logistic model with a binomial link function was used. The process of adjustment of the model was developed in two stages. First, the individual effects of each predictor variable were estimated, selecting among them the significant ones. Secondly, those having non-significant effects were discarded, following a parsimonious model. It is concluded that the variables that directly affect the dropout are the predictors of first order, Approved Branches (RA), List Order (OL), Civil Status (EC) and Parent Education (EP)
\end{abstract}

Keywords: dropout; logistic model; higher education; educational inequality; statistical analysis 


\section{INTRODUCCIÓN}

Desde el año 2007 a la fecha el número de estudiantes matriculados en el Sistema de Educación Superior Chileno ha crecido de manera sostenida, alcanzando una matrícula total al año 2016 de 1.178 .437 estudiantes, lo que representa un crecimiento del 57,7\%, según el Ministerio de Educación de Chile (MINEDUC, 2016). Sin embargo estas cifras no contemplan indicadores fundamentales en la progresión curricular estudiantil, tales como los índices de deserción ni las tasas de graduación oportuna, elementos fundamentales en la determinación de la calidad de la formación profesional, como mecanismo de aseguramiento de la calidad conforme a la normativa nacional vigente y al contexto político educacional. Por lo anterior, y dado que la sociedad chilena ve en la educación el camino más seguro hacia una vida de mayor prosperidad, según la Organización para la Cooperación y el Desarrollo (OCDE, 2009), es necesario conocer los motivos que llevan a los estudiantes a desertar, y con ello determinar los factores intervinientes en los procesos de aprendizaje y de enseñanza, para así poder implementar dispositivos efectivos que tiendan a disminuir la deserción y a aumentar las tasas de graduación.

Pero - ¿Cuáles son los efectos del fenómeno de la deserción universitaria? - , El informe sobre Educación Superior en América Latina y el Caribe (IESALC, 2000-2005), sostiene que los efectos negativos del fenómeno de la deserción en la educación superior, repercute al menos en cuatro dimensiones: dimensión social, en donde la deserción contribuye a la retroalimentación del círculo de la pobreza y la gestación de una capa social de frustrados profesionales, dimensión institucional, la que se ve coartada de cumplir su misión institucional afectando de manera importante los índices de eficiencia y de calidad, dimensión personal, en donde este fenómeno, en muchos casos, redunda en una sensación de frustración y fracaso del estudiante y finalmente dimensión económica, pues el informe estima que la deserción universitaria conlleva un elevado costo económico, alcanzando una pérdida que fluctúa entre los 2 y 415 millones de dólares por país.

El Servicio de Información de Educación Superior (SIES), en su informe anual de retención de alumnos de primer año, presentado en noviembre del año 2015, nos muestra la evolución que ha tenido el fenómeno de la deserción en la Educación Superior en estudiantes de primer año durante los años 2010 - 2014, el SIES establece que a nivel global, la deserción fluctúa en torno al 30\%, sin embargo el informe advierte que un número no menor de alumnos que desertan en primer año reingresan al sistema educativo, esto se ve reflejado en un estudio publicado el año 2012 por el SIES, el cual analizó al cohorte 2008, donde el 13,4\% de los estudiantes que desertaron reingresaron al sistema en los tres años siguientes, por lo que un 17,2\% de los estudiantes abandonaron definitivamente los estudios superiores. Por otro lado, el informe establece que las carreras con mayor tasa de deserción al primer año para la cohorte 2014, son las áreas de estudios relacionadas con las Humanidades y la Arquitectura con $27,6 \%$ y $29,2 \%$ respectivamente. El panorama regional muestra que para la cohorte 2014, las regiones que lideran la deserción al primer año son las regiones extremas: Atacama (42,5\%), Tarapacá (37,7\%), Antofagasta (35,2\%), Aysén $(33,1 \%)$ y Arica y Parinacota $(32,2 \%)$. Finalmente, en términos de género, los hombres muestran una tasa de deserción al primer año más alta que la de las mujeres (32,6\% versus 26,9\% para la cohorte 2014).

La Universidad de Playa Ancha (UPLA) no está ajena a esta problemática, en este sentido la Unidad de Análisis Institucional (UAI), perteneciente a la Dirección General de Análisis y Planificación Estratégica Institucional (DAPEI), ha definido y caracterizado al alumno desertor como aquel estudiante que abandona la institución, es decir no formaliza su proceso de matrícula en los plazos determinados y/o aquel estudiante que no continua con su programa formativo en la carrera a la cual ingresó, en base a esta caracterización, la UAI, en su anuario estadístico 2015, muestra incremento en la tasa de deserción de más de 10 puntos entre los años 2008-2013, alcanzando una tasa media de 20,26\%, tres puntos sobre la media nacional. Si desglosamos los porcentajes de la deserción por Facultad (Tabla 1), podemos observar que la Facultad que presenta mayor porcentaje de deserción, es Ingeniería alcanzando una tasa media de $41,55 \%$, en contraposición la Facultad de Salud es la que presenta las menores tasas de deserción con un promedio de $11,3 \%$.

A pesar de reconocer que se está frente a un gran problema (Díaz, 2008; Donoso y Schiefelbein, 2007; De los Ríos y Canales, 2007; Díaz, 2009), en Chile los estudios destinados a reconocer y cuantificar los motivos que llevan a los estudiantes a desertar del sistema de educación superior son escasos. Es en este sentido que el presente trabajo se ha planteado la necesidad de alcanzar los siguientes objetivos: (1) Identificar los factores que influyen, de manera significativa, en el proceso de deserción de los estudiantes de la Universidad de Playa Ancha, (2) Cuantificar el efecto individual de cada predictor en la respuesta de un modelo estadístico de regresión logística. Todo lo anterior con el propósito de implementar un modelo jerárquico de variables causales que denominaremos - Raíz jerárquica de tercer orden de variables causales de la deserción universitaria - el que nos permitirá tener una visión global de aquellos predictores de primer, segundo y tercer orden que explican de manera significativa el fenómeno de la deserción estudiantil en la Universidad de Playa Ancha. 
Tabla 1: Cuadro Comparativo de la Tasa de Deserción en las distintas Facultades de la Universidad de Playa Ancha, a partir de los datos de la Unidad de Análisis Institucional.

\begin{tabular}{lcccc}
\hline \multicolumn{1}{c}{ Facultad } & 2012 & 2013 & 2014 & 2015 \\
\hline C. Naturales & $21,5 \%$ & $17,1 \%$ & $25,7 \%$ & $30,2 \%$ \\
Ingeniería & $30,7 \%$ & $43,6 \%$ & $43,7 \%$ & $48,2 \%$ \\
Educación & $10,3 \%$ & $14,5 \%$ & $11,5 \%$ & $19,3 \%$ \\
Ed. Física & $15,9 \%$ & $22,2 \%$ & $17,7 \%$ & $20,5 \%$ \\
Salud & $10,5 \%$ & $12,2 \%$ & $10,4 \%$ & $12,2 \%$ \\
Humanidades & $17,2 \%$ & $20,9 \%$ & $25,4 \%$ & $23,2 \%$ \\
C. Sociales & $10,8 \%$ & $37,9 \%$ & $24,6 \%$ & $23,5 \%$ \\
\hline
\end{tabular}

\section{MARCO TEÓRICO}

Uno de los autores más influyentes en el estudio de la deserción universitaria es Vincent Tinto (1975) quien establece, que el problema que presentan las investigaciones que intentan estudiar este fenómeno, es gatillado fundamentalmente por dos deficiencias iniciales, la primera de estas dice relación con una falta de rigurosidad a la hora de definir conceptualmente la deserción en la Educación Superior, pues esta inexactitud ha llevado a agrupar, bajo el concepto de deserción, comportamientos o fenómenos muy diferentes, un ejemplo de esto es la no diferenciación de la deserción como una consecuencia de un bajo rendimiento académico y la deserción voluntaria o la deserción de una institución para irse a otra, para Tinto esta falta de rigurosidad conceptual puede llevar a conclusiones erradas y hasta contradictorias. Por otro lado una segunda deficiencia dice relación con la inadecuada conceptualización del proceso de deserción, esto puede verse reflejado, según Tinto en la escasa atención que se ha prestado a los modelos teóricos longitudinales.

Es en este sentido que Himmel (2002), define y caracteriza la deserción como el abandono prematuro de los estudios sin alcanzar la obtención del título o grado, distinguiendo en esta acción la deserción voluntaria e involuntaria, por su parte Cabrera et al. (2006), establece que la "deserción" es el término utilizado para referirse a una variedad de situaciones en el proceso educativo de los estudiantes con un elemento común, la interrupción de los estudios antes de concluirlos, por su parte Tinto (1982) define como desertor a cualquier estudiante que no tiene actividad académica durante tres semestres consecutivos, lo que es conocido como "primera deserción", a pesar de esta Tinto (1989) establece que no existe una definición de la deserción que capte plenamente este fenómeno, e invita a los investigadores a elegir la definición que mejor se ajusta a la investigación que se lleva a cabo, aceptando la invitación realizada por el autor, en este trabajo se entenderá como alumno desertor aquel estudiante que no tenga actividad académica durante tres semestres consecutivos.

En Chile las investigaciones destinadas a estudiar el fenómeno de la deserción universitaria son escasas y fundamentalmente destinadas a cuantificar la magnitud del fenómeno (Himmel, 2002), sin embargo han permitido dar luces de aquellos factores que intervienen significativamente en la deserción, lo que ha permitido ir caracterizando este fenómeno, en este sentido Larroucau (2013), estableció que la deserción puede ser explicada por un conjunto de variables, las cuales son agrupadas en cuatro dimensiones, a saber: dimensión individual del estudiante (notas de enseñanza media, ranking de notas y en menor medida los puntajes de selección universitaria PSU); dimensión socioeconómica (nivel de ingreso y ayuda estudiantil); dimensión característica del colegio de origen (puntajes PSU del colegio e índice de vulnerabilidad del colegio) y finalmente la dimensión institucional (calidad de la universidad y el tipo de carrera al cual accede el estudiante), por otro lado Paura y Arhipova (2014), concluyen que las variables que afectan de manera significativa en la deserción de estudiantes de primer año son las calificaciones obtenidas por los alumnos en secundaria, el género y el currículo académico de las carreras, en este mismo sentido Esteban et al (2017) afirman que el rendimiento académico en la universidad es la variable más influyente en la permanencia del estudiante en su institución, por su parte Pascual (2017) en un trabajo de corte cualitativo, llegó a concluir que las variables que más pesan al momento de desertar de la universidad son las limitaciones financieras, el bajo rendimiento académico, el factor de proximidad o lejanía con la universidad, el desagrado con la carrera y problemas de relaciones personales.

\section{Modelos Teóricos}

Los estudios que abordan el problema de la deserción universitaria, se sustentan mayoritariamente en los modelos teóricos desarrollados por Bean (1982), Spady (1970) y Tinto (1975), siendo el diferencial entre estos modelos, los factores que intervienen y que finalmente gatillan en la deserción del estudiante, en el 
primer modelo, los factores son externos a la universidad, pues estos impactan en las actitudes y en las decisiones de los estudiantes durante su permanencia en la institución, mientras que en el segundo modelo, esta decisión depende de la integración que logre el estudiante con el ambiente académico y social de la universidad (Castaño, Gallón, Gómez y Vásquez, 2004), siendo la combinación de ambos modelos teóricos la que mejor explica los procesos que afectan la decisión de desertar del sistema universitario (Cabrera, Castañeda, Nora y Hengstler, 1992), a continuación se presenta una síntesis de estos modelos.

\section{Modelo de Bean (1982)}

El modelo teórico de Bean (1982), nace como una adaptación del modelo de productividad desarrollado en el contexto de las organizaciones laborales (Himmel, 2002), Bean (1982) incorpora las variables de integración social y de integración académicas, definidas en el modelo de Tinto, como variables organizacionales, pues el modelo establece que la deserción universitaria puede verse de manera análoga a la productividad. Por otro lado, el autor asume que los factores externos a la universidad pueden adquirir gran relevancia, ya que estos impactan en las actitudes y en las decisiones que los estudiantes tomen a lo largo de permanencia en la institución. Finalmente, el autor sostiene que la insatisfacción con los estudios se asemeja a la insatisfacción con el trabajo, y determina que esta variable influye directamente en la intención de desertar de la institución.

Modelo de Spady (1970)

Spady (1970) sustenta su modelo en la teoría del suicidio desarrollada por Durkheim, y parte del supuesto que el proceso de deserción se explica de mejor manera asumiendo un enfoque interdisciplinario que involucre la interacción entre los atributos particulares del estudiante, tales como la disposición al estudio, las actitudes, las habilidades, entre otras y el entorno universitario en los cuales el autor distingue los cursos, los profesores, los administrativos, las autoridades y los compañeros, un resultado exitoso en esta interacción institución-estudiante le proporcionará a este último la oportunidad de afrontar con mayor éxito las exigencias académicas y las exigencias sociales al interior de la universidad, lo que permitirá aumentar las probabilidades de terminar con éxito sus estudios.

Spady (1970) sostiene que la decisión de desertar, puede verse influenciada fuertemente por la falta de integración de los estudiantes en el entorno de la educación superior, para el autor esta integración debe darse en dos ámbitos distintos pero complementarios, como son la integración académica y la integración social. Por otro lado, Spady (1970) señala que el medio familiar es una de las principales fuentes que exponen a los estudiantes a influencias, expectativas y demandas, afectando su nivel de integración social en la universidad y el ambiente familiar sobre el potencial académico y la congruencia normativa.

\section{Modelo de Tinto (1975)}

El modelo teórico de Tinto (1975), es uno de los modelos más influyentes en el estudio de la deserción universitaria (Donoso y Schiefelbein, 2007) el cual sustenta sus principales lineamientos en el trabajo desarrollado por Spady, entre los años 1970-1971 y en la teoría del suicidio de Durkheim (Cabrera et al, 1992). En la teoría del suicidio de Durkheim existen dos aspectos importantes, en primer lugar se establece que cuando una persona comparte valores con un grupo, la probabilidad de que el individuo se suicide se reduce, por otro lado cuando una persona cuenta con un soporte o apoyo de "amistad", esta persona tiene menos probabilidad de suicidarse (Spady, 1970), en este sentido Durkheim determina que el suicidio varía inversamente con el grado de integración de los grupos sociales de los que forma parte el individuo, bajo esta premisa Tinto nos propone hacer el ejercicio de ver a la institución universitaria como un micro mundo social, con sus propias complejidades, estructuras sociales y estructuras valóricas, que la hacen única en su cosmovisión, y así poder analizar y estudiar, de forma razonable, el fenómeno de la deserción de manera similar al del suicidio, entendiendo que las consecuencias que generan ambos fenómenos no son comparables.

Siguiendo esta línea argumentativa, es factible suponer que los factores que inciden en la decisión de desertar del sistema universitario son la escasa o nula interacción del estudiante con el "otro", entendiendo a este otro como el conjunto de individuos que componen la sociedad universitaria, tales como docentes, alumnos, administrativos, autoridades, etc. y la falta de "conexión" con los lineamientos y patrones valóricos de la institución, luego la falta de integración en la vida social de la universidad por parte del estudiante, redundará en una baja sensación de pertenencia lo que inevitablemente llevará a un aumento en la probabilidad de desertar del sistema universitario.

Tinto establece que su modelo teórico debe ser visto como un proceso longitudinal y sostiene que la integración académica, la integración social y un conjunto de características individuales del estudiante, tales como las expectativas educativas, el compromiso con sus metas, el compromiso con la institución y la 
motivación, se relacionan directamente con la continuidad o con distintos tipos de deserción universitaria, en este sentido el modelo establece que el estudiante ingresa a la universidad con una gama de atributos, experiencias preuniversitarias y antecedentes familiares, tales como su sexo, puntaje de ingreso, su promedio de notas de enseñanza media, sus logros académicos, sus relaciones sociales, su condición socioeconómica, sus expectativas, entre otras, atributos que afectan de forma directa o indirecta en la performance del estudiante en la universidad. Por otro lado y como un elemento fundamental del modelo teórico de Tinto, son las expectativas y los compromisos que el estudiante trae consigo al mundo universitario, ya que es la interacción entre el compromiso que el estudiante tiene con el hecho de finalizar sus estudios universitarios y el compromiso con la institución que lo acoge, la que determinará en gran medida la decisión de desertar del sistema universitario.

\section{MARCO METODOLÓGICO}

Basándonos en los fundamentos de la investigación social de Michael Crotty (1998), nuestra investigación es contextualizada en un paradigma positivista, utilizando técnicas cuantitativas de tipo explicativo, con técnicas estadísticas del tipo descriptivas, correlacional e inferencial, la población de estudio está constituida por los estudiantes matriculados en las Carreras de Geografía, Pedagogía en Matemática, Pedagogía en Física, Pedagogía en Biología y Pedagogía en Química cohorte 2014-2015, con un total de 169 estudiantes, todas ellas pertenecientes a la Facultad de Ciencias Naturales y Exactas de la Universidad de Playa Ancha, (ver tabla 2), con respecto a las variables predictivas estas fueron divididas en cuatro dimensiones, a describir: dimensión individual, dimensión académica, dimensión institucional y dimensión socioeconómica (Castaño et al, 2004), la investigación contó con una variable de respuesta o dependiente de carácter dicotómica donde cada estado es definido por, "El estudiante deserta de la Universidad" o "El estudiante No deserta de la Universidad" y una batería de variables predictoras o independientes, la base de datos fue obtenida a través de la Unidad de Análisis de la Universidad.

Tabla 2: Descripción de la muestra de estudiantes de la Facultad de Ciencias, Universidad de Playa Ancha.

\begin{tabular}{|l|c|c|c|}
\hline \multicolumn{1}{|c|}{ Carrera } & Cohorte 2014-2015 & $\begin{array}{c}\text { Estudiantes que } \\
\text { desertan }\end{array}$ & Porcentaje de deserción \\
\hline Geografía & 48 & 15 & $31,25 \%$ \\
\hline Ped. Biología & 36 & 8 & $22,22 \%$ \\
\hline Ped. Física & 14 & 2 & $14,28 \%$ \\
\hline Ped. Química & 14 & 4 & $28,57 \%$ \\
\hline Ped. Matemática & 57 & 23 & $40,35 \%$ \\
\hline \multicolumn{1}{|c|}{ Total } & 169 & 52 & $30,76 \%$ \\
\hline
\end{tabular}

\section{Consideraciones éticas}

La información de los estudiantes que fueron obtenidos a través de la Unidad de Análisis Institucional, y que son utilizados en esta investigación son de carácter reservados y contamos con el consentimiento informado de la Universidad de Playa Ancha.

\section{Modelo}

La investigación la hemos caracterizado como explicativa, por lo que subyace un modelo relacional entre los predictores $\mathrm{X}$ y la respuesta $\mathrm{Y}$, este modelo involucra un error, que viene a asumir el diferencial entre lo que observamos y lo que realmente es, funcionalmente esto es indicado como $Y=f(X)+e$, donde $e$ representa el error, por tanto las predicciones que realicemos sobre la respuesta $Y$, serán en términos esperados, es decir, "¿cuál será el valor esperado de la respuesta $Y$, dado que conocemos y observamos los datos $X$ ?", lo que simbólicamente expresamos por $E[Y / X]$, ahora bien esta representación condicional, adquiere diferentes formas dependiendo de la naturaleza de lo que queremos explicar, como en este estudio la variable de respuesta o dependiente $\mathrm{Y}$, es una variable de carácter dicotómica (deserta (1) o No deserta (0)) y la variable explicativa o independiente $X$, es la matriz de diseño asociada a un conjunto de variables, entonces el modelo que responde a estas características y que fue utilizado en esta investigación, es el modelo de regresión logística, que funcionalmente tiene la forma de la ecuación (1):

$E[Y / X]=\frac{\exp \left(\beta_{0}+\sum_{i=1}^{k} \beta_{i} X_{i}\right)}{1+\exp \left(\beta_{0}+\sum_{i=1}^{k} \beta_{i} X_{i}\right)^{\prime}}$ 
En la ec. (1), los parámetros $\beta_{i}, i=1, \ldots, k$ son características poblacionales desconocidas, que en función de la muestra observada debieron ser estimados por el método de máxima verosimilitud, esto tomando en cuenta las buenas propiedades asintóticas que presentan estos estimadores, la importancia de este proceso de estimación es que nos permitió establecer el riesgo relativo ante el incremento en una unidad en algún predictor específico.

\section{Análisis de datos}

El análisis de datos se desarrolló siguiendo las siguientes etapas:

Etapa correlacional: se aplicaron pruebas correlacionales, cuyo criterio de decisión fue el p-valor, en un nivel de significancia del $5 \%$, las técnicas utilizadas dependieron del nivel de medición de las variables que se sometieron a correlación (Hernández, Fernández y Baptista, 2014). Esta etapa buscó identificar la anidación de variables o variables de efectos indirectos.

Etapa Inferencial: se aplicaron pruebas de contrastes de medias para poder asumir igualdad de estratos, todas basadas en el criterio de decisión del p-valor y considerando un nivel de significancia del $5 \%$.

Ajuste del Modelo: se propone un modelo explicativo, indicando variables causales de primer, segundo y tercer orden, procurando un modelo parsimonioso. Todas las variables constituyentes del modelo están a un nivel de significancia del $5 \%$.

Finalmente es importante precisar que el poder predictivo del modelo alcanza un $56 \%\left(r^{2}=0.568\right)$, siendo considerada significativa con un nivel de significancia del $5 \%$ y criterio de decisión de $p$-valor. ( $p$-valor $=$ $0.00)$

\section{Raíz Jerárquica de Tercer Orden.}

La raíz jerárquica de tercer orden es una metodología organizacional propuesta por los autores para facilitar la visualización de los grados de dependencia de un conjunto de predictores a partir de una variable respuesta. La metodología se estructura en tres pasos: Paso 1: determinación de predictores de efecto significativo sobre la respuesta, los cuales constituyen el primer orden de explicación de la variable respuesta; Paso 2: especificar como respuesta cada una de las variables significativas de paso 1, y sobre ellas definir una regresión múltiple o un modelo lineal generalizado en coherencia con la variable, (modelo Binomial) por ejemplo. En esta etapa se identifican las variables de efectos significativos sobres las variables de primer nivel jerárquico; y Paso 3: repetir paso 2 con cada una de las variables de efecto significativo de segundo orden. Es decir, se identifican las variables de efectos significativos de las variables de efecto significativo de segundo orden.

Esta estructuración permite especificar las variables de efectos directos e indirectos, además de poder cuantificar el impacto sobre la variable de respuesta original. Cuando una metodología de estructuración jerárquica es aplicada en la explicación de la variable deserción, es posible identificar las variables que le competen por ejemplo a la institución formadora, o identificar sobre cuales variables es posible intervenir y por lo tanto optimizar el uso de recursos o esfuerzos.

\section{RESULTADOS Y DISCUSIÓN}

Los resultados son presentados en consistencia con la construcción de la raíz jerárquica de tercer orden, para ello fueron desarrollados cada uno de los tres pasos antes descritos. Para el desarrollo de los tres pasos se hace necesario la especificación de la notación mostrada en la Tabla 3 Los resultados se organizan en tres dimensiones caracterizadas por el orden jerárquico que ocupan los predictores.

Tabla 3: Nombre y Codificación de las Variables Predictoras del modelo

\begin{tabular}{|l|l|l|}
\hline \multicolumn{1}{|c|}{ V. Primer Orden } & \multicolumn{1}{c|}{ V. segundo Orden } & V. Tercer Orden \\
\hline Orden de Lista (OL) & PSU (PSU) & NEM (NEM) \\
\hline$N^{\circ}$ Ramos Aprobados (RA) & Año de Egreso de enseñanza media (AE) & Sexo(SX) \\
\hline Estado Civil (EC) & Con quien Vives (CV) & \\
\hline Educación del Padre (EP) & Ingresos (IN) & \\
\hline & Trabajo(TR) & \\
\hline & Educación de la Madre (EM) & \\
\hline
\end{tabular}




\section{Análisis de las variables de Primer Orden}

En esta dimensión se explicitan los efectos y significatividad de las variables predictoras, teniendo en consideración que la variable de respuesta es dicotómica (Bernoulli process). Son identificadas cuatro variables predictoras de primer orden (Fig.1), Orden de Lista (OL) que consiste en la posición que ocupa el estudiante en su registro de ingreso a su carrera $(1,2, \ldots, n)$, número de Ramos Aprobados (RA), Estado Civil (EC), la cual es caracterizada por 5 estados: soltero (1), casado (2), separado (3), viudo (4), otros (5) y finalmente la Educación del Padre (EP) siendo una variable caracterizada por 12 estados: sin estudios (1), básica incompleta (2), básica completa (3), media incompleta (4), media completa (5), centro de formación técnica incompleta (6), centro de formación técnica completa (7), universitaria incompleta (8), universitaria completa (9), instituto profesional incompleta (10), instituto profesional completa (11) y otros estudios (12).

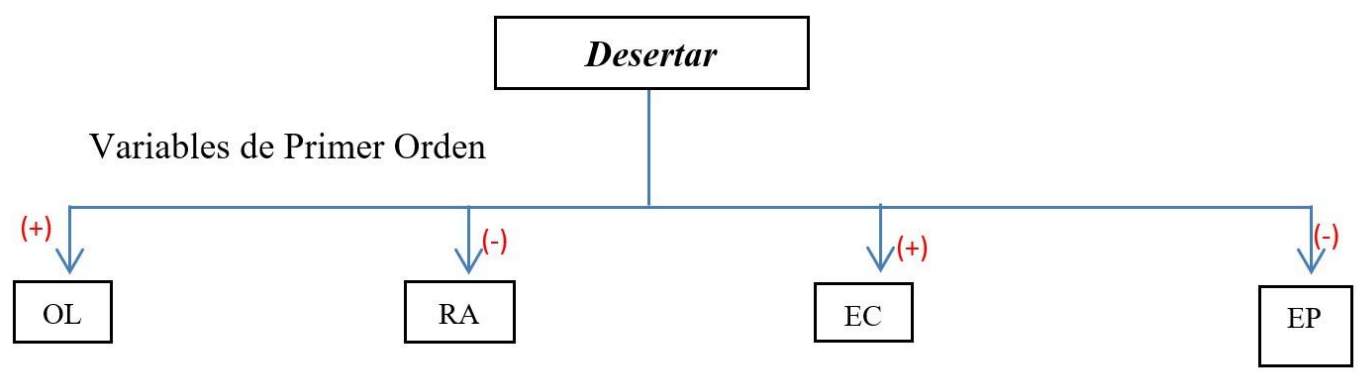

Fig.1: Variables predictoras, significativas al 5\%, de Primer Orden de la deserción.

Con respecto al efecto de cada variable predictora de primer orden se indica que Ramos Aprobados (RA) y Educación del Padre (EP) presentan efectos de tipo negativo sobre la respuesta, esto significa que incrementos unitarios en las variables predictoras se traduce en la disminución de la probabilidad de desertar. En el caso de los predictores Orden de Lista (OL) y Estado Civil (EC) los efectos son positivos, es decir que incrementos unitarios en estas variables se traducen en un aumento en la probabilidad de desertar. Finalmente, y en relación a los "Odds Ratios" de cada variable predictora de primer orden, se puede establecer que: el aumento en una unidad del nivel de (EP) y manteniendo las otras variables fijas, las probabilidades de desertar disminuyen en 1.811 veces, en el caso de los (RA) un aumento en una unidad implica una disminución en las probabilidades de desertar en 2.082 veces. Ahora para el caso de los predictores OL y EC hay un aumento en las probabilidades de desertar de 0.987 y 0,738 veces respectivamente. En este último caso el incremento unitario se traduce en un cambio de estado, por ejemplo pasar de soltero a casado.

\section{Análisis de las variables de Segundo Orden}

La especificación de las redes para las variables de segundo orden está basada en un modelo lineal generalizado, en este caso particular modelo de regresión lineal múltiple, ya que no se tiene la restricción de la dicotomía en las respuestas. Basado en la Fig.2, se visualiza la utilización de la simbología (+) y (-), lo que hace referencia al efecto que tiene sobre cada variable predictor, ahora asumida como respuesta. Por ejemplo (PSU) está acompañada del signo (-) en relación a (OL), esto significa que incrementos en el puntaje (PSU) se traducen en disminución en el número de posición en el orden de lista (OL). Disminuir en el orden de lista significa un número menor como etiqueta de su posición. De manera similar para (PSU) acompañado del signo (+) en relación a (RA), significa que por incrementos en el puntaje (PSU) se tiene incrementos en el rendimiento académico (RA).

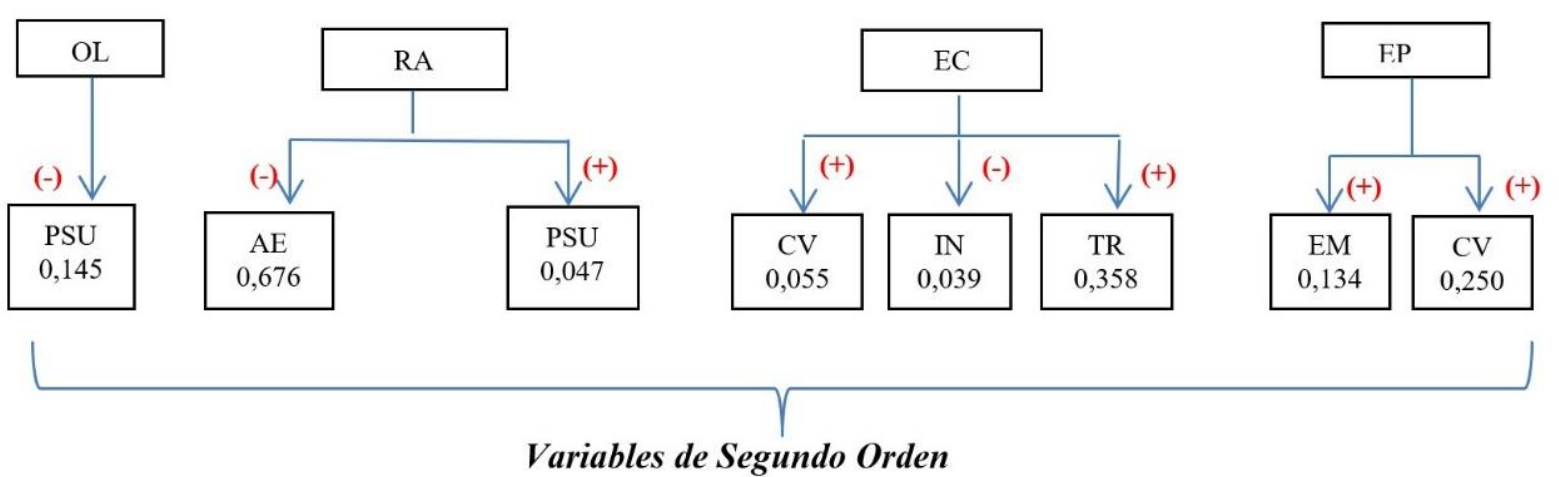

Fig.2: Variables predictoras anidadas de Segundo Orden. 
En esta dimensión se identifican siete variables predictoras de segundo orden, Puntaje de Selección Universitaria (PSU), Año de Egreso (AE), Personas con quien vive el estudiante durante sus estudios (CV), variable caracterizada por cinco estados: Con sus Padres (1), Con Familiares (2), Independiente (3), En pensiones (4) y otros (5), Ingreso Bruto Familiar (IN) caracterizada por doce estados: ]0-\$144.000] (1), ] $\$ 144.000-\$ 288.000]$ (2), ..., ] \$1.584.000- más] (12), Trabaja Actualmente (TR), No (1), Ocasionalmente (2) y Si (3) y por último Nivel de Educación de la Madre, variable caracterizada por 12 estados: sin estudios(1), básica incompleta (2), básica completa (3), media incompleta (4), media completa (5), centro de formación técnica incompleta (6), centro de formación técnica completa (7), universitaria incompleta (8), universitaria completa (9), instituto profesional incompleta (10), instituto profesional completa (11) y otros estudios (12). Finalmente, el valor asociado a las variables, en la Fig.2, establece el efecto que tiene cada predictor sobre la respuesta (en este nivel las respuestas son las variables de primer orden), por ejemplo, la variable (PSU) tiene un efecto positivo de 0,047 sobre la variable (RA), lo que significa que aumentar en una unidad el puntaje (PSU) afecta directamente en el aumento medio de Ramos aprobados (RA) en 0,047.

\section{Análisis de las variables de Tercer Orden}

El análisis de las variables de tercer orden sigue la misma dinámica del análisis anterior, en esta dimensión se identifican dos variables predictoras de tercer orden, Las Notas de Enseñanza Media y el Sexo del estudiante, caracterizado por Hombre (1) y Mujer (2). Se puede observar que en la Fig.3 el predictor (NEM) tiene asociado un signo positivo (+) con la respuesta (PSU), luego si aumentamos el promedio de Notas de Enseñanza Media (NEM) esto redundará en un aumento en la variable (PSU), con respecto al efecto particular de los predictores se puede establecer, por ejemplo, que el aumento en una unidad de la variable (NEM), se traducirá en el aumento promedio de 36,585 puntos en la (PSU).

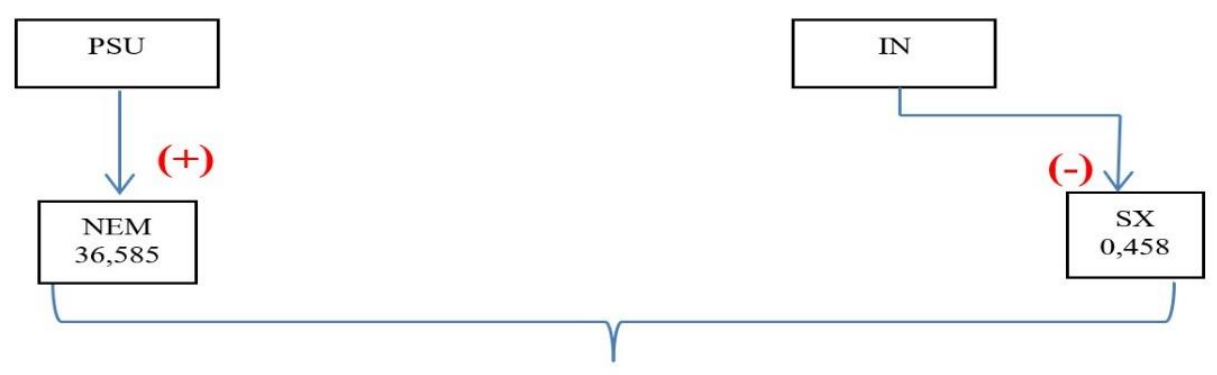

Variables de Tercer Orden

Fig.3: Variables predictoras anidadas de Tercer Orden.

Raíz jerárquica de tercer orden de para la deserción universitaria.

En función de cada una de las etapas antes descritas, como consecuencia de los tres pasos, se presenta la Raíz jerárquica de tercer orden para la deserción universitaria. En esta raíz jerárquica (Fig.4) podemos observar las relaciones existentes en los diferentes niveles entre los predictores y sus respuestas, por ejemplo en el tercer orden la variable (NEM) tiene un efecto positivo sobre la variable de segundo orden (PSU), es decir aumentar una unidad del (NEM) permite incrementar el puntaje (PSU) medio en 36,585 puntos, por otro lado el predictor (PSU) de segundo orden está relacionado negativamente con la variable (OL), es decir que aumentar el puntaje (PSU), redundará en disminuir en el orden de lista (OL), lo cual implica estar más cerca de los primeros lugares de la lista, finalmente la variable de primer orden (OL) está relacionada positivamente con la variable "desertar", es decir si aumento en una unidad el descriptor (OL), aumenta la variable desertar, lo que implica un aumento en la probabilidad de desertar.

El modelo propuesto permite establecer que un alto nivel educacional de los padres repercute en una disminución de la probabilidad de desertar, resultados similares obtuvieron Yao et al (2017), por otro lado un estudiante que presenta altas calificaciones en su trayectoria escolar y un buen puntaje de ingreso a la universidad, tiene mayor probabilidad de aprobar los ramos en su malla formativa, lo que redundará en una disminución de la probabilidad de desertar, en este mismo sentido Paura y Archipova (2014), establecieron que las variables que afectan significativamente a la deserción de los estudiantes de primer año son los planes de estudios de la facultad, las calificaciones de secundaria y el género, variables que están recogidas en la presente investigación.

En términos institucionales, la investigación arroja resultados que deben ser considerados, por ejemplo el número de ramos aprobados es una variable de primer orden que impacta directamente en la disminución de la probabilidad de desertar, por lo que se hace evidente establecer estrategias institucionales que 
permitan disminuir las tasas de reprobación, en este sentido una política de acompañamiento tutorial al estudiante, la posibilidad de contar con ayudantías y programas de nivelación, son estrategias que pueden ayudar a disminuir las tasas de deserción.

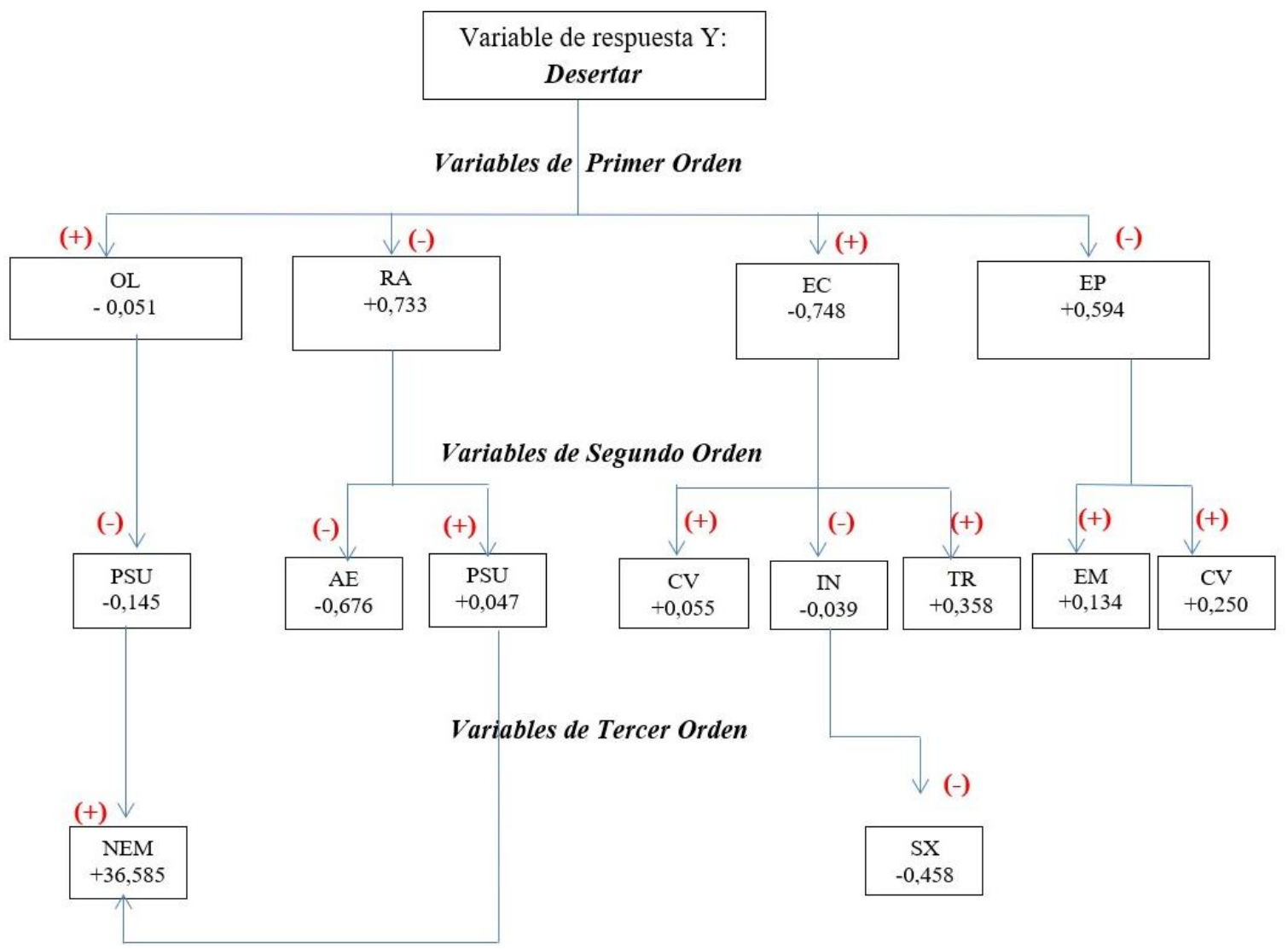

Fig.4: Variables predictoras y anidadas que configuran la Raíz Jerárquica de Tercer Orden del fenómeno de la deserción.

\section{CONCLUSIONES}

Las principales conclusiones obtenidas en el desarrollo de la presente investigación son:

(1) Los factores que intervienen en la decisión de desertar por parte de los estudiantes de la facultad de ciencias de la Universidad de Playa Ancha, pertenecen a la dimensión Académica del estudiante y a la dimensión socioeconómica de la familia, ambas dimensiones concordantes con otros estudios en Chile y Latinoamérica.

(2) La organización de las variables predictoras, a través de una Raíz Jerárquica de tercer orden presentó dos interesantes beneficios a la hora de analizar y explicar el fenómeno de la deserción, en primer lugar facilita la visualización global de los grados de dependencias del conjunto de variables predictoras a partir de la respuesta, lo cual facilita el análisis y la toma de decisiones institucionales y en segundo lugar permitió perturbar, de forma indirecta, variables de primer orden a través de la intervención de variables de segundo o tercer orden, lo que aumenta el campo de acción de las instituciones académicas en pos de disminuir las tasas de deserción.

\section{AGRADECIMIENTOS}

Los autores agradecen al programa de Doctorado en Política y Gestión Educativa de la Universidad de Playa Ancha, Valparaíso Chile. El presente trabajo fue apoyado y financiado por la Universidad de Playa Ancha, a través del proyecto DGI CNE 06-1718

\section{REFERENCIAS}

Bean, J.P. Student attrition, intentions, and confidence: Interaction effects in a path model. Research in higher education, 17(4), 291-320 (1982)

Cabrera, A.F., Castañeda, M.B., Nora, A., y Hengstler, D. The convergence between two theories of college persistence. The Journal of higher Education, 63(2), 143-164 (1992) 
Cabrera, L., Bethencourt, J.T., Pérez, P.A., y Afonso, M.G. El problema del abandono de los estudios universitarios. Relieve, 12(2),171-203. Disponible en: goo.gl/ZisXET (2006)

Castaño, E., Gallón, S., Gómez, K. y Vásquez, J. Deserción estudiantil universitaria: una aplicación de modelos de duración. Lecturas de Economía, 60(60), 39-65 (2009)

Castaño, E., Gallón, S., Gómez, K., y Vásquez, J. Análisis de los factores asociados a la deserción estudiantil en la Educación Superior. Revista de Educación, 345, 255-280 (2008)

Crotty, M. The foundations of social research: Meaning and perspective in the research process. London, Sage Publications (1998)

Datos, C. M. Informe final: estudio sobre causas de la deserción universitaria. Santiago: Universidad de Chile. Disponible en: https://goo.gl/GnV9Jc (2008)

De los Rios, D., y Canales, A. Factores explicativos de la deserción universitaria. Calidad en la Educación, (26), 173-201 (2007)

Díaz Peralta, C. Modelo conceptual para la deserción estudiantil universitaria chilena. Estudios pedagógicos (Valdivia), 34(2), 65-86. Disponible en: https://goo.gl/kZ8mcz (2008)

Díaz, C.J. Factores de deserción estudiantil en ingeniería: una aplicación de Modelos de duración. Información Tecnológica, 20(5), 129-145. Disponible en: https://goo.gl/JMQuEK (2009)

Dirección General de Análisis y Planificación Estratégica Institucional DAPEI. Anuario Estadístico. Disponible en: https://goo.gl/ujKyAz (2015)

Donoso, S., y Schiefelbein, E. Análisis de los modelos explicativos de retención de estudiantes en la universidad: una visión desde la desigualdad social, Estudios pedagógicos (Valdivia), 33(1), 7-27. Disponible en: https://goo.gl/fXBbe4 (2007)

Espinoza Díaz, Ó. E. D., y González, L. E. Políticas de educación superior en Chile desde la perspectiva de la equidad. Sociedad y Economía, (22), 69-94 (2012)

Esteban, M., Bernardo, A., Tuero, E., Cervero, A., y Casanova, J. Variables influyentes en progreso académico y permanencia en la universidad. European Journal of Education and Psychology, 10(2), 75-81 (2017)

Hernández Sampieri, R., Fernández Collado, C., y Baptista Lucio, P. Metodología de la investigación. Sexta Edición. Editorial Mc Graw Hill. México (2014)

Himmel, E. Modelos de análisis de la deserción estudiantil en la educación superior. Revista Calidad en la educación, 17(2), 91-108 (2002)

Informe matrícula 2016 Educación Superior en Chile, Santiago de Chile, MINEDUC. Disponible en: https://goo.gl/mhX3xX (2016)

International Institute for Higher Education in Latin America. Informe sobre la educación superior en América Latina y el Caribe, 2000-2005: la metamorfosis de la educación superior. IESALC. (2006)

Larroucau De Magalhaes-Calvet, T. Estudio de los factores determinantes de la deserción, en el sistema universitario chileno (2013)

OCDE La Educación Superior en Chile, Ministerio de Educación, Gobierno de Chile (2009)

Pascarella, E.T., y Terenzini, P.T. Predicting freshman persistence and voluntary dropout decisions from a theoretical model. The Journal of Higher Education, 51(1), 60-75 (1980)

Pascual, P.A.L. Factors Linked to Dropout Rate in a College Entrepreneurship Program. International Journal of Innovative Knowledge Concepts, 5(2), (2017)

Paura, L., y Arhipova, I. Cause analysis of students' dropout rate in higher education study program. Procedia-Social and Behavioral Sciences, 109, 1282-1286 (2014)

Servicio de Información de Educación Superior SIES. Panorama de la Educación Superior en Chile 2014. Disponible en: https://goo.gl/WtMf8e (2014)

Spady, W. G. Dropouts from higher education: An interdisciplinary review and synthesis. Interchange, 1(1), 64-85 (1970)

Tinto, V. Dropout in Higher Education: A Review and Theoretical Synthesis of Recent Research. Review of Education Research, 45(1), 89-125 (1975)

Tinto, V. Definir la deserción: una cuestión de perspectiva. Revista de Educación Superior, 71(18), 1-9 (1989)

Tinto, V. Misconceptions mar campus discussions of student retention. The Chronicle of Higher Education, 36(1), B2 (1989)

Yao, Y., Yi, H., Zhang, L., Huan, W., Yang, C., Shi, Y., e Rozelle, S. Exploring dropout rates and causes of dropout in upper-secondary vocational schools (2017) 